Article

\title{
Clinical Predictors of Neurogenic Lower Urinary Tract Dysfunction in Persons with Multiple Sclerosis
}

\author{
Janina Beck 1,+(D), Anke Kirsten Jaekel 1,2,*,+(D), Federico Leopoldo Zeller ${ }^{2}$, Michael Kowollik ${ }^{2}$, Ines Kurze ${ }^{3}$, \\ Albert Kaufmann ${ }^{4}$, Wolfgang Feneberg ${ }^{5}$, Anna Brandt ${ }^{6}$, Peter Flachenecker ${ }^{7}$, Thomas Henze ${ }^{8}$, \\ Burkhard Domurath ${ }^{9}$, Paul Schmidt ${ }^{10}$, Will Nelson Vance ${ }^{9}$, Franziska Goldschmidt ${ }^{1}$, \\ Ruth Klara Maria Kirschner-Hermanns ${ }^{1,2} \mathbb{D}$ and Stephanie C. Knüpfer ${ }^{1}$
}

check for

updates

Citation: Beck, J.; Jaekel, A.K.; Zeller, F.L.; Kowollik, M.; Kurze, I.;

Kaufmann, A.; Feneberg, W.; Brandt, A.; Flachenecker, P.; Henze, T.; et al Clinical Predictors of Neurogenic Lower Urinary Tract Dysfunction in Persons with Multiple Sclerosis. Diagnostics 2022, 12, 191. https:// doi.org/10.3390/diagnostics12010191

Academic Editors: Robert Živadinov and Dejan Jakimovski

Received: 30 November 2021

Accepted: 11 January 2022

Published: 13 January 2022

Publisher's Note: MDPI stays neutral with regard to jurisdictional claims in published maps and institutional affiliations.

Copyright: (C) 2022 by the authors. Licensee MDPI, Basel, Switzerland. This article is an open access article distributed under the terms and conditions of the Creative Commons Attribution (CC BY) license (https:// creativecommons.org/licenses/by/ $4.0 /)$.
1 Department for Neuro-Urology, Clinic for Urology, University Hospital Bonn, 53127 Bonn, Germany; Janina.beck@gmx.de (J.B.); Franziska.Goldschmidt@ukbonn.de (F.G.);

Ruth.Kirschner-Hermanns@ukbonn.de (R.K.M.K.-H.); stephanie.knuepfer@ukbonn.de (S.C.K.)

2 Neuro-Urology, Johanniter Neurological Rehabilitation Center 'Godeshoehe e.V.', 53177 Bonn, Germany; f.zeller@godeshoehe.de (F.L.Z.); kowollik@godeshoehe.de (M.K.)

3 Center of Spinal Cord Injuries and Diseases, Department for Paraplegiology and Neuro-Urology, 99438 Bad Berka, Germany; ines.kurze@zentralklinik.de

4 Department of Neuro-Urology, Kliniken Maria Hilf GmbH, 41063 Moenchengladbach, Germany; Albert.Kaufmann@mariahilf.de

5 Marianne Strauss Clinic Berg, Therapeutical Center for Patients with Multiple Sclerosis Kempfenhausen GmbH, 82335 Berg, Germany; wolfgang.feneberg@ms-klinik.de

6 Clinic Segeberg, Neurological Center, 23795 Bad Segeberg, Germany; anna.brandt@segebergerkliniken.de

7 Neurological Rehabilitation Center Quellenhof, 75323 Bad Wildbad, Germany; Peter.Flachenecker@Sana.de

8 Neurological Outpatient Practice Dr. Blersch, 93059 Regensburg, Germany; Thomas.Henze@outlook.com

9 Neuro-Urological Center, Clinic Beelitz GmbH, Neurological Rehabilitation Clinic, Beelitz-Heilstätten, 14547 Beelitz, Germany; bdomurath@yahoo.de (B.D.); Vance@kliniken-beelitz.de (W.N.V.)

10 Statistical Consulting for Science and Research, Große Seestr. 8, 13086 Berlin, Germany; paul.schmidt.mail@gmail.com

* Correspondence: a.k.jaekel@gmail.com; Tel.: +49-179-9033123

+ These authors contributed equally to this work.

Abstract: Background: Multiple sclerosis patients often develop neurogenic lower urinary tract dysfunction with a potential risk of upper urinary tract damage. Diagnostic tools are urodynamics, bladder diary, uroflowmetry, and post-void residual, but recommendations for their use are controversial. Objective: We aimed to identify clinical parameters indicative of neurogenic lower urinary tract dysfunction in multiple sclerosis patients. Methods: 207 patients were prospectively assessed independent of the presence of lower urinary tract symptoms. We analyzed Expanded Disability Status Scale scores, uroflowmetry, post-void residual, rate of urinary tract infections, standardized voiding frequency, and voided volume in correlation with urodynamic findings. Results: We found a significant correlation between post-void residual (odds ratio (OR) 4.17, confidence interval (CI) 1.20-22.46), urinary tract infection rate (OR 3.91, CI 1.13-21.0), voided volume (OR 4.53, CI 1.85-11.99), increased standardized voiding frequency (OR 7.40, CI 2.15-39.66), and urodynamic findings indicative of neurogenic lower urinary tract dysfunction. Expanded Disability Status Scale shows no correlation. Those parameters (except post-void residual) are also associated with reduced bladder compliance, as potential risk for kidney damage. Conclusion: Therefore, bladder diary and urinary tract infection rate should be routinely assessed to identify patients who require urodynamics.

Keywords: multiple sclerosis (MS); neuro-urology; neurogenic lower urinary tract dysfunction (NLUTD); Expanded Disability Status Scale (EDSS); post-void residual (PVR); upper urinary tract damage (UUTD); prospective study; bladder diary (BD) 


\section{Introduction}

Neurogenic lower urinary tract dysfunction (NLUTD) is a common and debilitating manifestation of multiple sclerosis (MS). For many people with MS, urinary symptoms may be the most important socially disabling consequences of the condition [1].

Although urinary symptoms are rare (3-10\%) at the first presentation of MS, up to $90 \%$ of patients experience neurogenic lower urinary tract symptoms (NLUTS) over the course of their disease [2]. Patients suffer mostly from detrusor overactivity (DO) (65\%), hypocontractile detrusor (25\%), and detrusor sphincter dyssynergia (DSD) (35\%) [3].

The severity of MS is rated using the Expanded Disability Status Scale (EDSS) [4]. This scale assesses the level of disability in a range of functional systems, including the bowel and lower urinary tract, to deliver a total score of 0 to 10 . Some studies reported several EDSS threshold levels indicative of NLUTD [5-7]. One study found correlations between EDSS $\geq 5.0$ and risk factors for upper urinary tract damage (UUTD) [8]. However, a uniform EDSS threshold does not exist.

Furthermore, there is no consensus on the optimal urological management of MS, although several European national panels have published their own guidelines for such patients [2]. These guidelines are nevertheless contradictory [2], and there is no uniform recommendation regarding referral for urodynamic studies (UDS) [8].

We therefore aimed to investigate clinical parameters and EDSS concerning their predictive value for NLUTD and the risk for UUTD in people with MS.

\section{Materials and Methods}

\subsection{Patients and Assessment}

We prospectively included 207 patients with MS originating from 6 clinics specializing in neuro-urology between February 2017 to June 2019.

Inclusion criteria were age $>18$ years and written informed consent.

We excluded persons with age $<18$ years, non-neurogenic lower urinary tract symptoms (LUTS), pregnancy or breastfeeding, untreated acute lower UTI, or without written informed consent.

All patients completed a two-day bladder diary (BD) to capture data on voided volume per micturition and $24 \mathrm{~h}$ voiding frequency.

In addition, we conducted uroflowmetry [9] (including post-void residual (PVR)) and UDS according to ICS standards [10]. Every patient was assessed by EDSS. Information on the occurrence of treated UTIs in the last 6 months was gathered in the patient history.

We investigated correlations between EDSS $\geq 5$ and risk factors for UUTD in our cohort. We chose the EDSS threshold of $\geq 5$ with regard to the study by Ineichen et al. [8] and defined the risk factors for UUTD as DO combined with DSD or a reduced bladder compliance $<20 \mathrm{~mL} / \mathrm{cm} \mathrm{H} \mathrm{H}_{2} \mathrm{O}$ accordingly.

In a further step, we assessed our data to find a threshold value of EDSS regardless of a pre-set threshold which indicates a risk of UUTD or NLUTD.

UDS findings indicative of NLUTD were defined according to current doctrine [9]: first desire to void $<100 \mathrm{~mL}$ or strong desire to void $<250 \mathrm{~mL}$ or abnormal sensation or bladder capacity $<250 \mathrm{~mL}$ or bladder compliance $<20 \mathrm{~mL} / \mathrm{cm} \mathrm{H} \mathrm{H}_{2} \mathrm{O}$ or any type of $\mathrm{DO}$ or DSD.

Furthermore, we assessed the correlation between different clinical parameters and pathological UDS indicative of NLUTD and potential UUTD. We defined the clinical parameters as follows:

Voided volume (VV)

Urinary tract infections (UTI) rate

$24 \mathrm{~h}$ standardized voiding frequency (SVF)

Post-void residual (PVR)

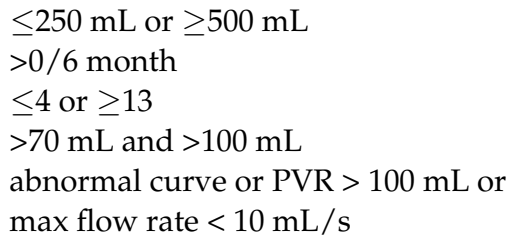

Uroflowmetry [9]

The cut-off values of VV were chosen according to a preliminary analysis of our study cohort and according to good urodynamic practice [9]. The thresholds of SVF, UTI, 
and PVR were defined according to the results of a previous investigation [11]. Voiding frequency was standardized (SVF) to a daily urine outtake of $2000 \mathrm{~mL}$. The following formula was used [11]:

$$
\mathrm{SVF}=\frac{2000 \mathrm{~mL}}{\text { voided volume }(\mathrm{mL} / 24 \mathrm{~h})} \times \varnothing \text { voiding frequency. }
$$

The cut-off values and diagnostics of uroflowmetry were defined according to good urodynamic practice [9].

In addition, we analyzed the correlation between combinations of our defined clinical parameters and pathological UDS findings defined by Ineichen et al. [8] with regard to the potential risk of UUTD:

- $\quad$ Correlation between $\mathrm{SVF} \geq 13+\mathrm{VV} \leq 250 \mathrm{~mL}$ and compliance $<20 \mathrm{~mL} / \mathrm{cm} \mathrm{H}_{2} \mathrm{O}$.

- $\quad$ Correlation between SVF $\geq 13+$ PVR $>100 \mathrm{~mL}$ and DSD and DO.

- $\quad$ Correlation between UTI > 0/6 months + PVR > $100 \mathrm{~mL}$ and DSD and DO.

This study was conducted in accordance with the Declaration of Helsinki. All patients gave their written informed consent. Ethical approval (EK 313/13-University Hospital Bonn) was obtained.

\subsection{Statistical Analysis}

For all analyses, R language for statistical computing (Version 3.6.0, R Core Team 2019) was used [12]. A statistical assessment of the threshold EDSS was analyzed with $2 \times 2$ contingency tables. Clinical parameters correlated to risk factors for NLUTD and UUTD were analyzed with $2 \times 2$ contingency tables. Fisher's exact test was used to calculate odds ratios (OR's) and their $95 \%$ confidence limits. To assess the prognostic quality of the selected predictors, standard performance measures for binary classifiers were used, namely sensitivity (Sens), specificity (Spec), positive (PPV), and negative predictive values (NPV).

\section{Results}

\subsection{Patient Characteristics, Clinical Parameters, and UDS Findings}

We assessed 207 patients, of whom 69.1\% (141) were female and 30.9\% (63) were male. Patient and disease characteristics are summarized in Table 1.

Table 1. Patient and disease characteristics.

\begin{tabular}{lllll}
\hline & Mean (SD) & Median (25-75\%) & Min-Max & Missing \% (n) \\
\hline Age of patients in years & $49.2(10.7)$ & $49(41-55)$ & $19-75$ & $1.4 \%(3)$ \\
Age of MS onset in years & $35.5(11)$ & $34(28-42)$ & $14-71$ & $2.9 \%(6)$ \\
Disease duration in years & $13.7(9.5)$ & $13(6-20)$ & $0-46$ & $2.9 \%(6)$ \\
MS Type & $\%(n)$ & & & \\
PPMS & $10.9 \%(22)$ & & & \\
RRMS & $46.5 \%(94)$ & & & \\
SPMS & $42.6 \%(86)$ & & & \\
\hline
\end{tabular}

SD, standard deviation; MS, multiple sclerosis; PPMS, primary progressive MS; RRMS, relapsing remitting MS; SPMS, secondary progressive MS.

A summary of the collected parameters from BD, uroflowmetry, and UDS, as well as EDSS, is shown in Table 2. 
Table 2. Summary of the parameters of BD, uroflowmetry, UDS, and EDSS.

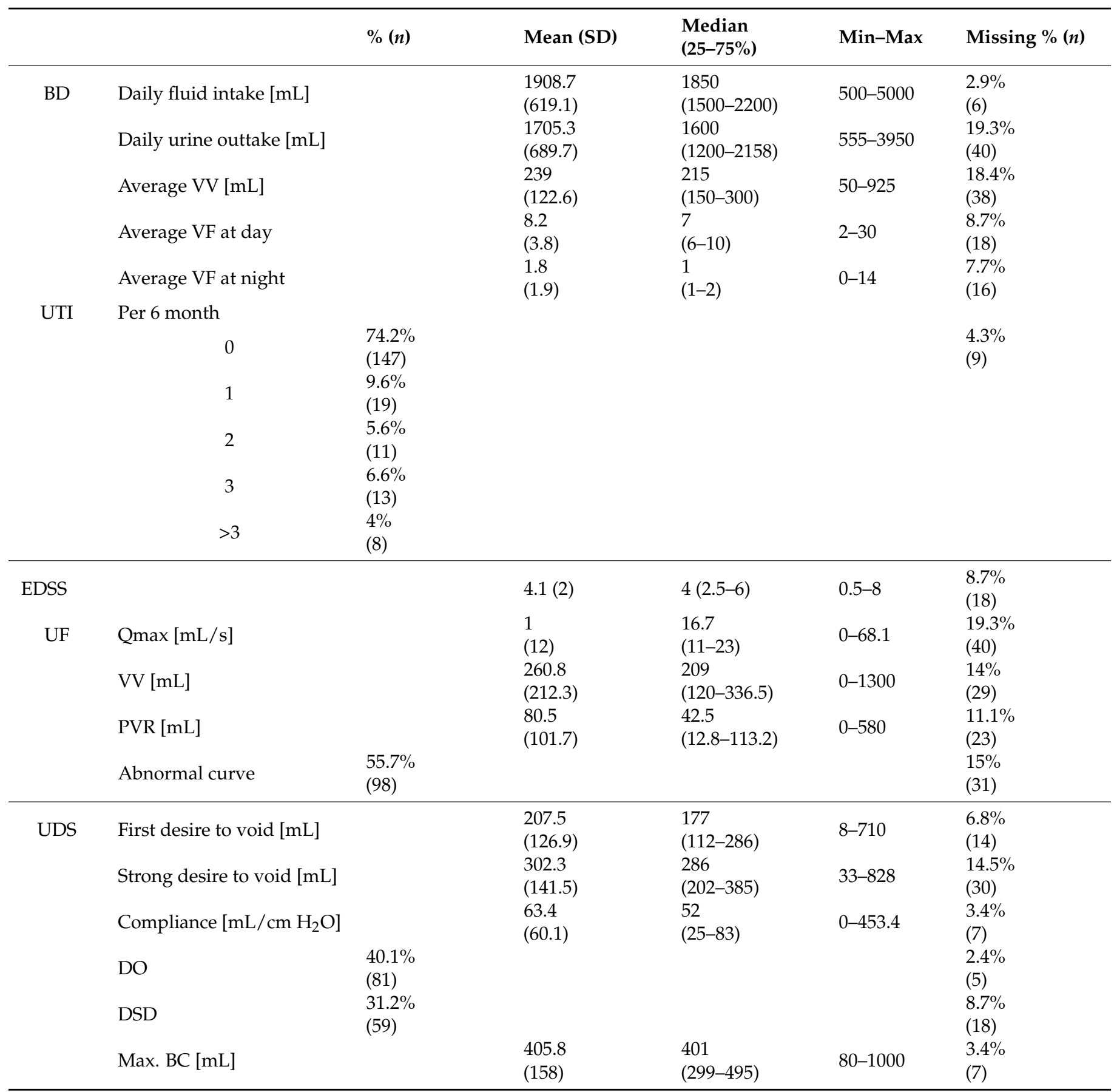

BD, bladder diary; SD, standard deviation; UTI, urinary tract infections; EDSS, Expanded Disability Status Scale $\mathrm{UF}$, uroflowmetry; VV, voided volume; VF, voiding frequency; PVR, post-void residual; Qmax, maximum uroflow; UDS, urodynamic study; DO, detrusor overactivity; DSD, detrusor sphincter dyssynergia; max. BC, maximum cystometric bladder capacity.

In our study, $83 \%$ (172) of patients with MS had a pathological UDS outcome indicative of NLUTD; $20 \%$ (39) showed risk factors for UUTD.

Furthermore, $79 \%(84 / 106)$ of asymptomatic patients (no urinary symptoms) showed abnormal UDS findings indicative of NLUTD, whereas 13\% (13/99) of asymptomatic patients showed risk factors for UUTD in their UDS findings. A summary of the presence of LUTS and UDS findings are shown in Table 3. 
Table 3. The presence of LUTS and UDS findings indicative of NLUTD and potential UUTD.

\begin{tabular}{cccc}
\hline & \multicolumn{2}{c}{ Symptomatology with Regard to NLUTD } \\
& $n$ & $\%$ & Abnormal UDS \\
& 101 & 87 & $n$ \\
\hline Symptomatic & 106 & 79 & 88 \\
Asymptomatic & \multicolumn{2}{c}{ Symptomatology with Regard to Risk of UUTD } \\
\hline & \multicolumn{3}{c}{ Abnormal UDS } \\
& 101 & $\%$ & $n$ \\
\hline Symptomatic & 99 & 26 & 26 \\
Asymptomatic & 13 & 13
\end{tabular}

LUTS, lower urinary tract symptoms; UDS, urodynamic studies; NLUTD, neurogenic lower urinary tract dysfunction; UUTD, upper urinary tract damage.

\subsection{EDSS Threshold}

The cohort was analyzed with regard to risk factors for UUTD in two patient groups: EDSS $<5$ vs. EDSS $\geq 5$.

The contingency table showed that there is no obvious difference between reduced compliance with an EDSS $<5$ vs. EDSS $\geq 5(16.7 \%$ vs. $12.7 \%$; Table 4$)$. A similar result is obtained for the patients with DO and DSD (9.3\% vs. $14.1 \%$; Table 4$)$.

Table 4. Frequency distribution of EDSS and potential risk factors for UUTD.

\begin{tabular}{|c|c|c|c|c|}
\hline \multirow{2}{*}{ EDSS } & \multicolumn{2}{|c|}{ Compliance $<20 \mathrm{~mL} / \mathrm{cm} \mathrm{H}_{2} \mathrm{O}$} & \multicolumn{2}{|c|}{ DO and DSD } \\
\hline & No & Yes & No & Yes \\
\hline$<5$ & $83.3 \%(95)$ & $16.7 \%(19)$ & $90.7 \%(107)$ & $9.3 \%(11)$ \\
\hline$\geq 5$ & $87.3 \%(62)$ & $12.7 \%(9)$ & $85.9 \%(61)$ & $14.1 \%(10)$ \\
\hline
\end{tabular}

DO, Detrusor overactivity; DSD, detrusor sphincter dyssynergia; EDSS, Expanded Disability Status Scale.

The data showed no significant differences between the two groups of EDSS $(<5$ and $\geq 5)$ concerning the risk of reduced compliance $(p=0.53)$ or DO and DSD $(p=0.34)$. The predictive power (Sens, Spec, PPV, NPV) of the EDSS threshold value of 5 is limited (Table 5).

Table 5. $p$-values and predictive parameters of EDSS and risk factors for UUTD.

\begin{tabular}{cclllll}
\hline & Odds Ratio & $p$-Value & Sens & Spec & PPV & NPV \\
\hline $\begin{array}{c}\text { Compliance } \\
<20 \mathrm{~mL} / \mathrm{cm} \mathrm{H}_{2} \mathrm{O}\end{array}$ & $0.73(0.27-1.82)$ & 0.53 & 0.32 & 0.61 & 0.13 & 0.83 \\
$\mathrm{DO}$ and DSD & $1.59(0.57-4.39)$ & 0.34 & 0.48 & 0.64 & 0.14 & 0.91 \\
\hline
\end{tabular}

UUTD, upper urinary tract damage; DO, detrusor overactivity; DSD, detrusor sphincter dyssynergia; Sens, sensitivity; Spec, specificity; PPV, positive predictive value; NPV, negative predictive value; significance level of $p$-value $<0.05$.

Data were analyzed to determine a threshold of EDSS that indicated NLUTD or potential UUTD (Figure 1). No increasing or decreasing trend was observed. The AUCperformance measures of the three parameters on the $y$-axis did not exceed 0.56. 

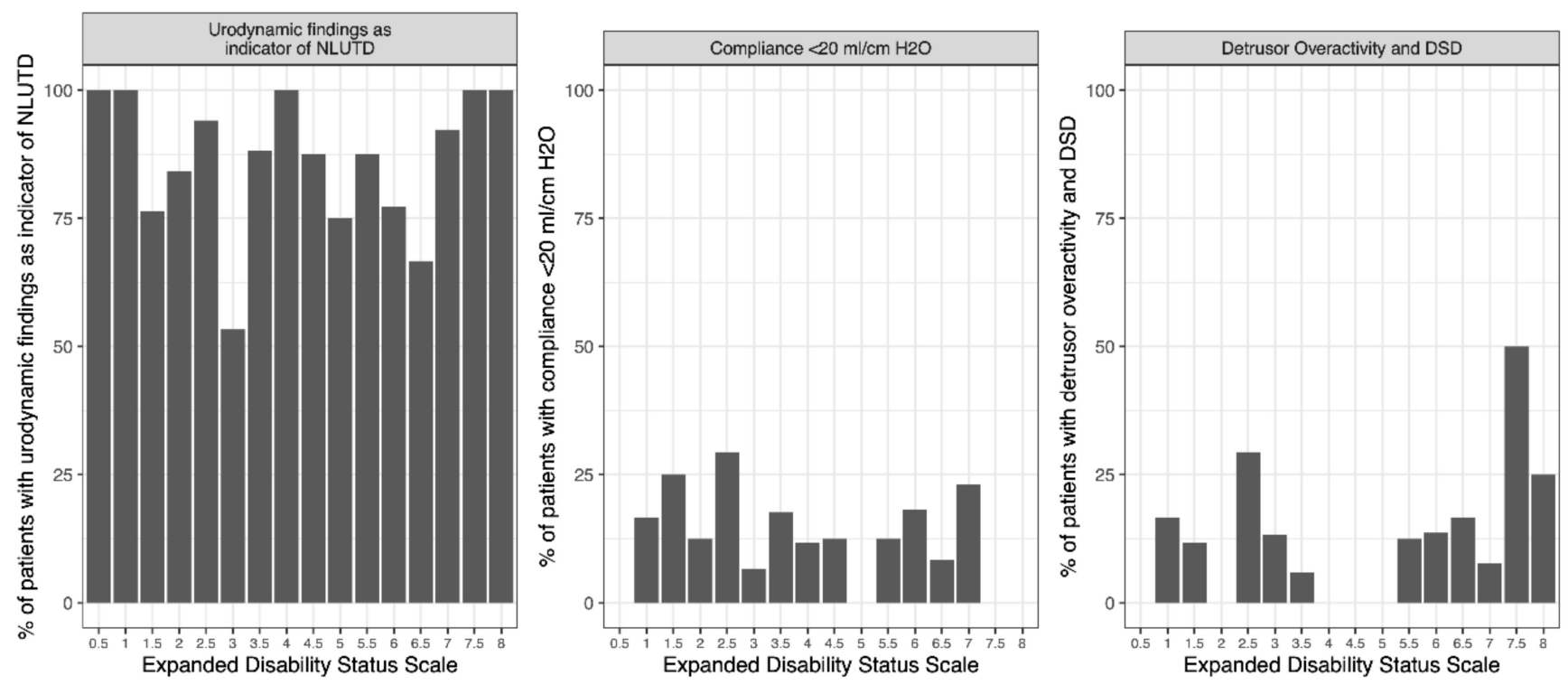

Figure 1. Analysis of Expanded Disability Status Scale threshold. NLUTD, neurogenic lower urinary tract dysfunction; DSD, detrusor sphincter dyssynergia.

\subsection{Correlations between Clinical Parameters and UDS Findings Indicative of NLUTD or Potential UUTD}

The following clinical parameters had significant correlations with UDS findings indicative of NLUTD: PVR $(p=0.02 / 0.00), \mathrm{SVF} \geq 13 / 24 \mathrm{~h}(p=0.00), \mathrm{VV} \leq 250 \mathrm{~mL}(p=0.00)$ and $\geq 500 \mathrm{~mL}(p=0.02)$, and UTI $>0 / 6$ months $(p=0.03)$ (Table 6$)$.

$\mathrm{VV} \geq 500 \mathrm{~mL}$ indicates a lower risk of NLUTD with OR 0.3 (CI 0.11-0.87) and $p$-value 0.02 , but the sensitivity is only $10 \%$. SVF $\leq 4 / 24$ h shows a significant effect on NLUTD with a $p$-value of 0.03 in two patients.

Significant correlations were found between reduced compliance and the following clinical parameters: $\mathrm{VV} \leq 250 \mathrm{~mL}(p=0.01), \mathrm{SVF} \geq 13 / 24 \mathrm{~h}(p=0.00)$ and UTI $>0 / 6$ months $(p=0.04)$; the OR was $>1.0 . \mathrm{VV} \leq 250 \mathrm{~mL}$ showed the best sensitivity with $83 \%$, but a low PPV (19\%). SVF $\geq 13 / 24 \mathrm{~h}$ and UTI $>0 / 6$ months showed a sensitivity of $66 \%$ and $43 \%$ (Table 6).

The correlation of clinical parameters with DO and DSD did not lead to a significant result.

Table 6. Relationship between clinical parameters and UDS indicative of NLUTD and between clinical parameters and reduced compliance.

\begin{tabular}{|c|c|c|c|c|c|c|}
\hline \multicolumn{7}{|c|}{ Urodynamic Findings Indicative of NLUTD } \\
\hline & Odds Ratio & $p$-Value & Sens & Spec & PPV & NPV \\
\hline $\mathrm{SVF} \leq 4 / 24 \mathrm{~h}$ & $0(0-1.06)$ & 0.03 & 0.00 & 0.94 & 0.00 & 0.16 \\
\hline $\mathrm{SVF} \geq 13 / 24 \mathrm{~h}$ & $7.4(2.15-39.66)$ & 0.00 & 0.44 & 0.90 & 0.96 & 0.25 \\
\hline $\mathrm{VV} \leq 250 \mathrm{~mL}$ & $\begin{array}{c}4.53 \\
(1.85-11.99)\end{array}$ & 0.00 & 0.64 & 0.72 & 0.91 & 0.31 \\
\hline $\mathrm{VV} \geq 500 \mathrm{~mL}$ & $0.3(0.11-0.87)$ & 0.02 & 0.10 & 0.72 & 0.62 & 0.15 \\
\hline Uroflowmetry & $1.91(0.75-5.02)$ & 0.20 & 0.54 & 0.62 & 0.81 & 0.31 \\
\hline PVR $>70 \mathrm{~mL}$ & $6.43(1.87-34.4)$ & 0.00 & 0.40 & 0.91 & 0.95 & 0.24 \\
\hline PVR > $100 \mathrm{~mL}$ & $\begin{array}{c}4.17 \\
(1.20-22.46)\end{array}$ & 0.02 & 0.30 & 0.91 & 0.94 & 0.21 \\
\hline UTI $>0 / 6$ months & $\begin{array}{c}3.91 \\
(1.13-21.00)\end{array}$ & 0.03 & 0.29 & 0.91 & 0.94 & 0.20 \\
\hline
\end{tabular}


Table 6. Cont.

\begin{tabular}{|c|c|c|c|c|c|c|}
\hline \multicolumn{7}{|c|}{ Compliance $<20 \mathrm{~mL} / \mathrm{cm} \mathrm{H}_{2} \mathrm{O}$} \\
\hline & Odds Ratio & $p$-Value & Sens & Spec & PPV & NPV \\
\hline $\mathrm{SVF} \leq 4 / 24 \mathrm{~h}$ & $0(0-28.03)$ & 1.00 & 0.00 & 0.99 & 0.00 & 0.84 \\
\hline$S V F \geq 13 / 24 h$ & $3.7(1.51-9.61)$ & 0.00 & 0.66 & 0.66 & 0.27 & 0.91 \\
\hline $\mathrm{VV} \leq 250 \mathrm{~mL}$ & $\begin{array}{c}3.91 \\
(1.22-16.56)\end{array}$ & 0.01 & 0.83 & 0.45 & 0.19 & 0.94 \\
\hline $\mathrm{VV} \geq 500 \mathrm{~mL}$ & $0.59(0.06-2.71)$ & 0.74 & 0.09 & 0.86 & 0.09 & 0.86 \\
\hline Uroflowmetry & $0.25(0.02-1.39)$ & 0.09 & 0.22 & 0.46 & 0.03 & 0.88 \\
\hline PVR > $70 \mathrm{~mL}$ & $0.75(0.27-1.94)$ & 0.66 & 0.30 & 0.64 & 0.13 & 0.84 \\
\hline PVR > 100 mL & $0.76(0.23-2.11)$ & 0.64 & 0.22 & 0.73 & 0.12 & 0.84 \\
\hline UTI $>0 / 6$ months & $2.52(1.03-6.10)$ & 0.04 & 0.43 & 0.77 & 0.25 & 0.88 \\
\hline
\end{tabular}

3.4. Influence of Combined Clinical Parameters on UDS Findings Indicative of Potential UUTD

The combination of SVF $\geq 13 / 24 \mathrm{~h}$ and $\mathrm{VV} \leq 250 \mathrm{~mL}$ showed a significant correlation with compliance $<20 \mathrm{~mL} / \mathrm{cm} \mathrm{H}_{2} \mathrm{O}$ (OR 3.36, CI 1.23-9.06, $\left.p=0.009\right)$. However, our data indicated a low sensitivity (0.46) and PPV (0.27).

A combined assessment of SVF $\geq 13 / 24 \mathrm{~h}$ and PVR $>100 \mathrm{~mL}$ with DO and DSD yielded no statistically significant evidence $(p=0.413)$.

A potential correlation was also observed between the combination of UTI $>0 / 6$ months and PVR $>100 \mathrm{~mL}$ with DO and DSD. This combination was not significant $(p=1.00)$.

\section{Discussion}

Several recommendations and consensus documents on the management of urinary disorders in multiple sclerosis patients propose that EDSS is a decision-making factor for further urological investigations [5,8,13-15]. However, no global threshold value of EDSS exists [2]. Furthermore, the clinical value with regard to storage and voiding symptoms is still unclear [16].

Our data demonstrate no reliable correlation between EDSS $\geq 5$ and the risk of UUTD. Furthermore, we found no other threshold value of EDSS that indicates NLUTD or the risk of UUTD. In contrast to our data, previous studies have demonstrated a significant association between EDSS and abnormal UDS findings [5-8]. However, only one study [8] investigated the correlation between EDSS and risk factors of UUTD, and it included only patients with lower urinary tract symptoms (LUTS). In contrast, we assessed a cohort that was not divided into LUTS and non-LUTS cases. This may have affected the detailed composition of the EDSS and thus biased the results. Ineichen et al. [8] stated that most patients with higher EDSS will have LUTS. Despite this, due to the impact of eight functional systems (pyramidal, cerebellar, brainstem, sensory, bowel and bladder, visual, cerebral, other) on the EDSS, patients with a similar EDSS are not necessarily a homogenous group in terms of LUTS. Wiedemann et al. [5] assessed only patients with LUTS and had a mean EDSS similar to ours: $4.5( \pm 2.3)$. Based on their findings, they recommended a UDS for all patients with EDSS $\geq 6.5$ [5]. In contrast, Nakipoglu et al. [17] investigated a cohort with and without LUTS. They did not establish a relationship between disease characteristics and urodynamic findings. Their mean EDSS was $5.1( \pm 2.2)$ and similar to the cohort with LUTS of Ineichen et al. [8]. A high diversity regarding correlations between EDSS, LUTS, and urodynamic findings also exists in other studies $[6,7,18]$. The inconsistent definition of pathological UDS findings and the bias of UDS interpretation hamper a comparison of the various studies. Nevertheless, the lack of a standard EDSS threshold is reflected in the different guidelines/recommendations. Italian [15] and Spanish [14] consensus documents recommend further neuro-urological examination based on an EDSS of 3, whereas a French algorithm emphasized an EDSS $\geq 6$ as a red flag for neuro-urological consultation [13]. In contrast, a recent multinational consensus statement [16] presented EDSS as a useful tool for measuring the progression of neurological disability, but in terms of assessing LUTS in 
persons with MS the consensus group recommends LUT-specific questionnaires instead of EDSS [16].

NLUTS are common symptoms among persons with MS [2] and can significantly impair quality of life [3]. Furthermore, NLUTD is the main reason for morbidity and hospitalization [6]. Nevertheless, published data suggest an under-diagnosis of NLUTD (up to $48 \%$ ) and non-optimized or under-treatment in persons with MS [14]. Previous studies have highlighted that a significant proportion of asymptomatic patients with MS have NLUTD [18,19], and the absence of symptoms is poorly reflected by UDS [3]. Focusing on asymptomatic patients, the present study revealed UDS results indicative of NLUTD in $79 \%$ of asymptomatic patients, whereas $13 \%$ of asymptomatic patients showed risk factors for UUTD. A similar result was described by Bemelmans et al. [18], who revealed abnormal UDS results in $52 \%$ of patients without any urinary complaints. They saw a hyposensitive bladder as a reason for this number of asymptomatic patients. These results are in line with Nakipoglu et al., who could not find a significant correlation between urinary symptoms and urodynamic findings [17]. However, this issue is reflected in different guidelines that recommend more in-depth examinations for asymptomatic patients $[14,15,19]$, even though the algorithms recommending UDS are different. In contrast, the UK consensus recommends bladder management corresponding to LUTS [20]: UDS is recommended only in the event of surgical treatment or if conservative treatment fails. The British expert panel pointed out that UDS results are unlikely to influence management procedures and UUTD is rare in persons with MS [20]. Similarly, the Turkish consensus report recommends invasive UDS only in the event of UUTD and/or failure of conservative treatment [21]. On the other hand, other guidelines state that adequate treatment can reduce the risk of UUTD or even prevent it, and it is essential to detect at-risk patients as early as possible [8,14]; therefore, there is a need for additional parameters indicating NLUTD regardless of the presence of LUTS. Our study showed that additional clinical parameters were useful for identifying patients who required further neuro-urological assessment. In addition to the well-known parameters PVR and rate of UTI, we found increased SVF to be indicative of NLUTD and UUTD. SVF was first assessed by Domurath et al. [11] as part of a newly evaluated algorithm in the neuro-urological assessment of persons with MS. A significant correlation between DO and SVF was found with a cut off $\geq 13 / 24 \mathrm{~h}, 95.5 \%$ of the patients showed abnormal UDS results [11]. We assessed increased SVF as a single parameter and obtained significant correlations to UDS findings indicative of NLUTD. Furthermore, our data showed a significant correlation with reduced bladder compliance, which is considered a risk factor for UUTD [8].

According to our data, another novel clinical parameter in terms of NLUTD is $\mathrm{VV} \leq 250 \mathrm{~mL}$. It proved to be indicative of NLUTD and the risk of UUTD and had the best prognostic performance of the tested parameters. VV has been shown to be a useful measure of efficacy regarding the medical treatment of overactive bladder (OAB) [22]. Van Brummen et al. [23] demonstrated an association between frequent symptoms of OAB and lower maximum VV. To the best of our knowledge, our study is the first to assess VV with regard to abnormal UDS findings in persons with MS and no cut-off of voided volume in relation to NLUTD exists; therefore, we used the cut-off value of $250 \mathrm{~mL}$ in accordance with our BD data. Even though the use of bladder diaries is recommended in several guidelines $[13,15,16,19]$, the recommended criteria for further investigations differ considerably $[15,19]$. None of the recommendations are based on the details of a BD, and all guidelines $[13,15,16,19]$ point out that a BD should be used if patients report LUTS.

For this reason, we must emphasize that urological symptoms in our study cohort poorly reflect abnormalities in SVF or VV. $52 \%$ of the asymptomatic patients with NLUTD had bladder diaries with a VV $\leq 250 \mathrm{~mL} .35 \%$ of the asymptomatic patients with NLUTD showed an SVF $\geq 13 / 24 \mathrm{~h}$. This underlines the need for an objective tool for determining abnormalities in voiding issues. A bladder diary can be this tool as it is a simple, non-invasive, and cost-efficient instrument for objectifying symptoms and disorders. Furthermore, the asymptomatic patients included almost $22 \%$ with UTI > 0/6 months; therefore, we recom- 
mend the routine use of a bladder diary and an assessment of UTIs in persons with MS. Those with VV $\leq 250 \mathrm{~mL}$, SVF $\geq 13 / 24 \mathrm{~h}$, or UTI $>0 / 6$ months should soon undergo UDS.

It must be noted that risk factors for UUTD were adopted from spina-bifida and spinal-cord-injury patients, who have a higher incidence of kidney damage than persons with MS [24]. Furthermore, it must be borne in mind that UDS in asymptomatic healthy individuals have generated variable results [25]. Finally, data were collected by highly specialized neuro-urological departments, and thus the recorded baseline characteristics of patients may deviate from those in less specialist settings.

\section{Conclusions}

Persons with MS should be examined for NLUTD regardless of LUTS. Our study revealed that voided volume $\leq 250 \mathrm{~mL}$, voiding frequency $\geq 13 / 24 \mathrm{~h}$, and UTI $>0 / 6$ months are clinical parameters indicative of NLUTD and the potential risk of UUTD in persons with MS. To determine these parameters, BD and an assessment of UTIs are mandatory for every patient with MS. Affected patients should soon undergo UDS.

Author Contributions: Conceptualization, B.D., R.K.M.K.-H. and S.C.K.; funding acquisition, R.K.M.K.-H.; investigation, F.L.Z., M.K., I.K., A.K., W.F., A.B., P.F., T.H., B.D. and W.N.V.; methodology, A.K.J.; project administration, J.B.; software, P.S.; supervision, S.C.K.; validation, P.S.; visualization, F.G.; writing-original draft, J.B. and A.K.J.; writing-review \& editing, A.K.J. and S.C.K. All authors have read and agreed to the published version of the manuscript.

Funding: Main funding was provided by the German charity fund, Förderverein zur Kontinenzforschung und Kontinenzaufklärung e.V.; Karmeliterhöfe, Karmeliterstr. 10, 52064 Aachen, Germany. (Grant No 17/002).

Institutional Review Board Statement: The study was conducted according to the guidelines of the Declaration of Helsinki, and approved by the Ethics Committee of University Hospital Bonn (protocol code EK 313/13).

Informed Consent Statement: Informed consent was obtained from all subjects involved in the study.

Data Availability Statement: The data presented in this study are available on request from the corresponding author. The data are not publicly available due to privacy.

Acknowledgments: The authors would like to thank the MS Consensus Group (partly funded by Coloplast), which developed an algorithm for classifying persons with MS and alerted us to the necessity of this research, and the neuro-urology team at the Johanniter Neurologic Rehabilitation Centre 'Godeshoehe e.V.', in Bonn, Germany.

Conflicts of Interest: The authors declare no conflict of interest.

\section{References}

1. Chancellor, M.B.; Blaivas, J.G. Urological and sexual problems in multiple sclerosis. Clin. Neurosci. 1994, 2, 189-195.

2. Aharony, S.M.; Lam, O.; Corcos, J. Evaluation of lower urinary tract symptoms in multiple sclerosis patients: Review of the literature and current guidelines. Can. Urol. Assoc. J. 2017, 11, 61-64. [CrossRef] [PubMed]

3. Litwiller, S.; Frohman, E.; Zimmern, P. Multiple sclerosis and the urologist. J. Urol. 1999, 161, 743-757. [CrossRef]

4. Kurtzke, J.F. Rating neurologic impairment in multiple sclerosis: An expanded disability status scale (EDSS). Neurology 1983, 33, 1444. [CrossRef] [PubMed]

5. Wiedemann, A.; Kaeder, M.; Greulich, W.; Lax, H.; Priebel, J.; Kirschner-Hermanns, R.; Füsgen, I. Which clinical risk factors determine a pathological urodynamic evaluation in patients with multiple sclerosis? An analysis of 100 prospective cases. World J. Urol. 2013, 31, 229-233. [CrossRef]

6. Giannantoni, A.; Scivoletto, G.; Di Stasi, S.M.; Grasso, M.G.; Agrò, E.F.; Collura, G.; Vespasiani, G. Lower urinary tract dysfunction and disability status in patients with multiple sclerosis. Arch. Phys. Med. Rehabil. 1999, 80, 437-441. [CrossRef]

7. Koldewijn, E.L.; Hommes, O.R.; Lemmens, W.A.; Debruyne, F.M.; van Kerrebroeck, P.E. Relationship between lower urinary tract abnormalities and disease-related parameters in multiple sclerosis. J. Urol. 1995, 154, 169-173. [CrossRef]

8. Ineichen, B.V.; Schneider, M.P.; Hlavica, M.; Hagenbuch, N.; Linnebank, M.; Kessler, T.M. High EDSS can predict risk for upper urinary tract damage in patients with multiple sclerosis. Mult. Scler. J. 2018, 24, 529-534. [CrossRef] 
9. Schäfer, W.; Abrams, P.; Liao, L.; Mattiasson, A.; Pesce, F.; Spangberg, A.; Sterling, A.M.; Zinner, N.R.; Kerrebroeck, P.V. Good urodynamic practices: Uroflowmetry, filling cystometry, and pressure-flow studies. Neurour. Urodyn. 2002, 21, 261-274. [CrossRef] [PubMed]

10. Rosier, P.F.W.; Schaefer, W.; Lose, G.; Goldman, H.B.; Guralnick, M.; Eustice, S.; Dickinson, T.; Hashim, H. International Continence Society Good Urodynamic Practices and Terms 2016: Urodynamics, uroflowmetry, cystometry, and pressure-flow study. Neurourol. Urodyn. 2017, 36, 1243-1260. [CrossRef]

11. Domurath, B.; Kurze, I.; Kirschner-Hermanns, R.; Kaufmann, A.; Feneberg, W.; Schmidt, P.; Henze, T.; Flachenecker, P.; Brandt, A.; Vance, W.N.; et al. Neurourological assessment in people with multiple sclerosis (MS): A new evaluated algorithm. Mult. Scler. Relat. Disord. 2020, 44, 102248. [CrossRef] [PubMed]

12. Team, R. Core. R: A Language and Environment for Statistical Computing; R Foundation for Statistical Computing: Vienna, Austria, 2017.

13. Amarenco, G.; Chartier-Kastler, E.; Denys, P.; Jean, J.L.; de Sèze, M.; Lubetzski, C. First-line urological evaluation in multiple sclerosis: Validation of a specific decision-making algorithm. Mult. Scler. J. 2013, 19, 1931-1937. [CrossRef] [PubMed]

14. Medina-Polo, J.; Adot, J.M.; Allué, M.; Arlandis, S.; Blasco, P.; Casanova, B.; Matías-Guiu, J.; Madurga, B.; Meza-Murillo, E.R.; Müller-Arteaga, C.; et al. Consensus document on the multidisciplinary management of neurogenic lower urinary tract dysfunction in patients with multiple sclerosis. Neurourol. Urodyn. 2020, 39, 762-770. [CrossRef] [PubMed]

15. Ghezzi, A.; Carone, R.; Del Popolo, G.; Amato, M.P.; Bertolotto, A.; Comola, M.; Del Carro, U.; Di Benedetto, P.; Giannantoni, A.; Lopes de Carvalho, M.L.; et al. Recommendations for the management of urinary disorders in multiple sclerosis: A consensus of the Italian Multiple Sclerosis Study Group. Neurol. Sci. 2011, 32, 1223-1231. [CrossRef]

16. Averbeck, M.A.; Iacovelli, V.; Panicker, J.; Schurch, B.; Finazzi Agrò, E. Urodynamics in patients with multiple sclerosis: A consensus statement from a urodynamic experts working group. Neurourol. Urodyn. 2020, 39, 73-82. [CrossRef]

17. Nakipoglu, G.F.; Kaya, A.Z.; Orhan, G.; Tezen, O.; Tunc, H.; Ozgirgin, N.; Ak, F. Urinary dysfunction in multiple sclerosis. J. Clin. Neurosci. 2009, 16, 1321-1324. [CrossRef]

18. Bemelmans, B.L.H.; Hommes, O.R.; Van Kerrebroeck, P.E.V.; Lemmens, W.A.J.G.; Doesburg, W.H.; Debruyne, F.M.J. Evidence for Early Lower Urinary Tract Dysfunction in Clinically Silent Multiple Sclerosis. J. Urol. 1991, 145, 1219-1224. [CrossRef]

19. De Sèze, M.; Ruffion, A.; Denys, P.; Joseph, P.-A.; Perrouin-Verbe, B. The neurogenic bladder in multiple sclerosis: Review of the literature and proposal of management guidelines. Mult. Scler. J. 2007, 13, 915-928. [CrossRef]

20. Fowler, C.J.; Panicker, J.N.; Drake, M.; Harris, C.; Harrison, S.C.W.; Kirby, M.; Lucas, M.; Macleod, N.; Mangnall, J.; North, A.; et al. A UK consensus on the management of the bladder in multiple sclerosis. Postgrad. Med. J. 2009, 85, 552-559. [CrossRef]

21. Çetinel, B.; Tarcan, T.; Demirkesen, O.; Özyurt, C.; Şen, İ.; Erdoğan, S.; Siva, A. Management of lower urinary tract dysfunction in multiple sclerosis: A systematic review and Turkish consensus report. Neurourol. Urodyn. 2013, 32, 1047-1057. [CrossRef]

22. Colli, E.; Parazzini, F.; Olivieri, L.; Cipriani, S.; Bertozzi, R.; Meschia, M.; Montorsi, F. Number of Daytime Micturitions and Volume Voided per Micturition in the Evaluation of Efficacy of Drugs for Overactive Bladder: Findings from Randomized Clinical Trials. Eur. Urol. 2007, 52, 525-530. [CrossRef] [PubMed]

23. Van Brummen, H.J.; Heintz, A.P.M.; van der Vaart, C.H. The association between overactive bladder symptoms and objective parameters from bladder diary and filling cystometry. Neurourol. Urodyn. 2004, 23, 38-42. [CrossRef] [PubMed]

24. Musco, S.; Padilla-Fernández, B.; Del Popolo, G.; Bonifazi, M.; Blok, B.F.M.; Groen, J.; ‘t Hoen, L.; Pannek, J.; Bonzon, J.; Kessler, T.M.; et al. Value of urodynamic findings in predicting upper urinary tract damage in neuro-urological patients: A systematic review. Neurourol. Urodyn. 2018, 37, 1522-1540. [CrossRef] [PubMed]

25. Wyndaele, J.; Wachter, S.D. Cystometrical Sensory Data from a Normal Population: Comparison of Two Groups of Young Healthy Volunteers Examined with 5 Years Interval. Eur. Urol. 2002, 42, 34-38. [CrossRef] 